\title{
MOVIMENTOS SOCIAIS DO CAMPO, EDUCAÇÃO DO CAMPO E PEDAGOGIA HISTÓRICO-CRÍTICA: ALGUMAS PROBLEMATIZAÇÕES
}

Andre Luiz de Souzal

RESUMO: Este artigo tem por objetivo discutir o pensamento Marxista em torno da Educação e a concepção epistemológica do conceito Educação do Campo, relacionando a teoria marxista com os elementos centrais da pedagogia do Campo. Utiliza-se, para isso, o método histórico dialético para compreensão da realidade. Nesse sentido, a Educação do Campo tem elementos cruciais do método dialético, pois, utiliza-se do sujeito como protagonista de seu desenvolvimento histórico, rompendo com as barreiras construídas da educação mercadológica. A Educação do Campo vem como uma crítica ao desenvolvimento atual da sociedade burguesa, que nega os direitos fundamentais da sociedade em geral, mais especificamente aos povos do campo. O movimento de Educação do Campo está construindo novos valores humanos, rompendo com os valores da educação capitalista que traz em seu bojo o meritocratismo, a competividade. A nova educação deve trazer em seu interior os valores da solidariedade e da coletividade. A Educação do Campo perpassa a educação formal, na qual o sujeito é apenas um receptor de informações e de conhecimento, mas vai além disso: ela constrói sujeitos capazes de edificar sua própria história.

Palavras-chave: Educação Campo; Marxismo; Movimentos Sociais do Campo.

\section{SOCIAL MOVEMENTS OF THE FIELD, FIELD EDUCATION AND HISTORICAL- CRITICAL PEDAGOGY: SOME PROBLEMATIZATIONS}

\begin{abstract}
The purpose of this article is to discuss the Marxist thought about Education and the epistemological conception of the concept of Field Education, relating the Marxist theory to the central elements of the field pedagogy. For this, the dialectical historical method for understanding reality is used. In this sense, Field Education has crucial elements of the dialectical method, since the subject is used as the protagonist of its historical development, breaking with the built barriers of marketing education. Field Education comes as a critique of the current development of bourgeois society, which denies the fundamental rights of society in general, more specifically to the peoples of the countryside. The Field Education movement is building new human values, breaking with the values of capitalist education that brings in its meritocratism, the competitiveness. The new education must bring within it the values of solidarity and of the community. Field education permeates formal education, in which the subject is only a receiver of information and knowledge, but goes beyond that: it builds subjects capable of building their own history.
\end{abstract}

Key-words: Education Field; Marxism; Social Movements of the Field.

\footnotetext{
${ }^{1}$ Mestre em Ciências Sociais pela UNIOESTE. Especialista em Educação do Campo e Agroecologia na Agricultura Familiar Camponesa - Residência Agrária pela UNIICAMP (2015). Licenciado e Bacharelado em Ciências Sociais pela UNIOESTE (2012). Professor EBTT de Sociologia do Instituto Federal do Paraná, Campus de Palmas. Contato: andre.souza@ifpr.edu.br; andresociais@ hotmail.com.
} 


\section{INTRODUÇÃO}

A discussão realizada neste artigo buscou analisar elementos essenciais em torno do tema Educação do Campo e do Marxismo. Sistematizamos fragmentos do pensamento de Marx e Engels sobre Educação, elencando uma nova percepção de Educação. Com base nos estudos desenvolvidos no campo da Educação, notamos que o materialismo histórico como base do processo educacional e a crítica à concepção de educação burguesa liberal que não considera os educandos como homens concretos, síntese das relações sociais, mas como homens abstratos.

A educação, para Marx e Engels, não só está diretamente ligada ao desenvolvimento material do mundo e aos interesses de classe, mas também tem um papel político e transformador social, uma práxis libertadora capaz de uma mudança de mentalidade e construção de uma nova ordem social.

Assim sendo, a Educação do Campo tem em seu método uma perspectiva crítica perante a sociedade burguesa, rompendo com as ideologias dominantes e forjando uma práxis revolucionaria dos povos do campo. Tal práxis está sendo construída por meio das lutas de classes.

Tendo esse cenário como pano de fundo, organizamos este texto da seguinte forma: primeiramente, teorizamos a perspectiva marxista sobre a apreensão da realidade; trabalhamos, na sequência, a categoria do Materialismo Histórico Dialético, contrapondo a perspectiva Idealista de Educação. A problematização repousou sobre a vinculação da filosofia com a realidade material, configurando assim, o foco da pedagogia Marxista e da Educação do Campo; finalmente, tratamos das lutas dos movimentos sociais do campo em prol da Educação do Campo. Com essa discussão, é possível sintetizarmos as diversas conquistas perante ao Estado nas formulações das Diretrizes para Educação do Campo. Essa discussão se faz necessária, tendo em visita que os povos do campo lutam diariamente contra o latifúndio, contra o agronegócio (expressão maior do capitalismo na atualidade), ao mesmo tempo em que buscam forjar sua própria educação, seu próprio jeito de fazer escola, seu próprio jeito de produzir sua existência.

\section{EDUCAÇÃO DO CAMPO E A SUA PERSPECTIVA EMANCIPATÓRIA}


Marx e Engels, no livro "A Ideologia Alemã", realizam uma crítica à concepção idealista da História ${ }^{2}$ e demonstram a necessidade da análise contextual e sociológica do período histórico do séc. XIX para uma possível transformação social na Alemanha e no Mundo. A crítica de Marx e Engels com relação ao idealismo hegeliano se dava na medida em que esse afirmava que é o pensamento que constitui o homem real e que as ideias são agentes fundamentais ou únicos da transformação histórica.

O materialismo Histórico ${ }^{3}$ desmistifica a inversão realizada pelos hegelianos, analisa a mentalidade social de baixo para cima, desce a filosofia dos céus para terra, reconhece que as ideias e seu desenvolvimento são frutos da evolução material dos homens e que não existe; portanto, história das ideias, mas uma história vivida e construída por "homens vivos" que com sua luta por sobrevivência e subsequente vivência desenvolve as relações de produção ${ }^{4}$. Essas diferenças mencionadas podem ser observadas na figura abaixo:

Figura 1: Comparações dos métodos

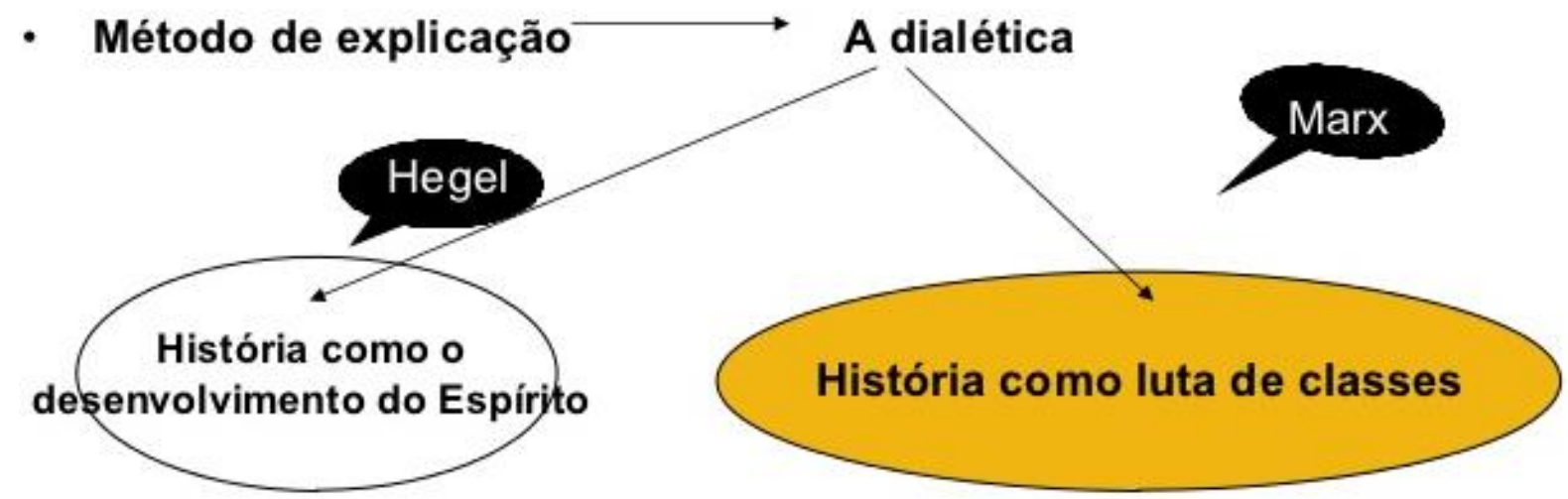

\section{IDEALISMO}

\section{MATERIALISMO}

Fonte: Elaborada pelos autores a partir de Marx e Engels (1993).

A mudança das relações de produção e seu o desenvolvimento é que geram as ideias, a filosofia, a religião, os valores morais, as leis, em suma, a mentalidade social. Assim, é a

\footnotetext{
2 O Idealismo Histórico entende as ideias ou a consciência como os agentes fundamentais ou únicos da transformação histórica.

${ }^{3} \mathrm{O}$ mundo das ideias é produto do mundo real e não do seu produtor.

${ }^{4}$ Relações sociais de produção referem-se às formas estabelecidas de distribuição dos meios de produção e do produto e ao tipo de divisão social do trabalho numa dada sociedade e em um período histórico determinado.
} 
realidade material que determina as ideias e não ao contrário, como podemos verificar na reflexão de Marx e Engels:

São os homens que desenvolvem a sua produção material e o seu intercâmbio material que, ao mudarem essa sua realidade, mudam também o seu pensamento e os produtos do seu pensamento. Não é a consciência que determina a vida é a vida que determina a consciência. (MARX; ENGELS, 1993, p.25).

Marx demonstra no materialismo histórico que a mentalidade social ou a "superestrutura social" é fruto do desenvolvimento das relações materiais vividas e construídas pelos homens. Esse processo é dialético, marcado pelo antagonismo de classe presente na "infra-estrutura social"4.

Observamos, então, que o desenvolvimento das ideias não é fruto delas mesmas, mas das relações materiais históricas construídas pelos Homens. A mentalidade burguesa do séc. XIX é uma construção histórica fruto do desenvolvimento dos meios materiais de vida: os "meios de produção".

No pensamento de Marx e Engels, a crítica aos hegelianos seria, portanto, a sistematização do materialismo histórico: a relação da filosofia com a vida e problemáticas sociais que afetam a situação do homem na sociedade burguesa. O significado do conhecimento em Marx parte do empirismo positivista ${ }^{5}$, no primeiro momento, na análise do objeto e na sua descrição e a partir desse momento de observação se realiza a abstração do objeto, sua conceituação geral, universal e científica.

Em um segundo momento, ocorre a inversão, o racionalismo idealista ${ }^{1}$, no qual as determinações abstratas retornam ao nível do concreto, como observado nas palavras do autor: "O primeiro passo reduziu a plenitude da representação a uma determinação abstrata; pelo segundo, as determinações abstratas conduzem à reprodução do concreto pela via do pensamento" (MARX, 1973, p.229).

Esse retorno, então, será a problemática da vinculação da filosofia com a realidade material, configurando, assim, o foco da pedagogia Marxista e da Educação do Campo. Nesse sentido, a educação para Marx não poderá ser pensada de forma independente ou desvinculada da realidade material do homem, mas as relações materiais devem ser pensadas como parte do processo de educação. Portanto, a Educação do Campo deve ser pensada e 
trabalhada em conjunto com a realidade dos sujeitos do campo, vinculada à sua base material e cultural, representado a ferramenta de luta dos povos do campo.

Assim, notamos o materialismo histórico como base do processo educacional e a crítica à concepção de educação burguesa que não considera os educandos como homens concretos, síntese das relações sociais, mas como homens abstratos. Os problemas educativos deixam, desse modo, de ser problemas de ideais gerais (abstrações) da humanidade e de categorias sagradas e passam a ser trabalhados como problemas históricos, de uma determinada época e de uma determinada sociedade.

O educador do campo não deve pensar que poderá estabelecer ideais educativos de forma arbitrária, sem reconhecer as etapas do processo de desenvolvimento histórico dos sujeitos, mas deve trabalhar a educação do campo dentro da evolução das relações materiais vividas pelo educando concreto-real.

A História como processo expresso na divisão do trabalho, no surgimento da propriedade privada e de uma sociedade classista, na qual o Estado é seu representante, levanos a pensar na ligação entre a ideia e os interesses históricos de classe, nos quais se encontra o conhecimento sistematizado, síntese das relações sociais. Sobre isso, Marx e Engels argumentam:

Os indivíduos que constituem a classe dominante possuem, entre outras coisas, uma consciência, e é em consequência disso que pensam; na medida em que dominam enquanto classe e determinam uma época histórica em toda extensão, é lógico que esses indivíduos dominem em todos os sentidos, que tenham, entre outras, uma posição dominante como seres pensantes, como produtores de ideias, que regulamentem a produção e distribuição dos pensamentos de sua época; as suas ideias são, portanto, as ideias dominantes de sua época. (MARX, ENGELS, 1993, p.47).

O educando concreto herda esse conhecimento sistematizado das gerações anteriores e se expressa na sua assimilação e, a partir desse conhecimento historicamente construído, ocupa seu papel na divisão social do trabalho. Para Marx,

Os homens fazem sua própria História, mas não a fazem como querem; não a fazem sob circunstância de sua escolha e sim sob aquelas com que se defrontam diretamente, legadas e transmitidas pelo passado. A tradição de todas as gerações mortas oprime como pesadelo o cérebro dos vivos. (MARX, 1997, p.25).

\footnotetext{
${ }^{5}$ Augusto Comte (1798-1857) foi o fundador do positivismo, extensão dos métodos científicos das ciências naturais ao estudo da sociedade: a criação de uma "sociologia" cientifica.
} 
A educação, para Marx e Engels, não só está diretamente ligada ao desenvolvimento material do mundo e interesses de classe, mas também tem um papel político e transformador social, uma práxis libertadora capaz de uma mudança de mentalidade e construção de uma nova ordem social.

Nesse sentido, a educação do campo tem como tarefa histórica a emancipação do homem do campo, sua libertação das ilusões ou "ideologias", mostrando-lhe as suas raízes sociais e gerando uma práxis revolucionária para modificar o mundo. Conforme Caldart (2003), existe uma nova prática de Escola que está sendo gestada nesse movimento. Nossa sensibilidade de educadores já nos permitiu perceber que existe algo diferente e que pode ser uma alternativa em nosso horizonte de trabalhador da educação, de ser humano. Essa nova perspectiva de Educação forja os novos sujeitos do campo protagonizando sua própria história. Para Marx e Engels,

Se o homem forma todos os seus conhecimentos, as suas sensações, etc. na base do mundo dos sentidos e da experiência dentro do mundo, trata-se, pois, consequentemente, de organizar o mundo empírico de modo que o homem se experimente a si mesmo enquanto homem. (MARX, ENGELS, 2003, p.39).

Em suma, a Educação do Campo fundamenta-se na análise do processo histórico. Essa concepção constitui um ponto de partida não só para crítica à sociedade burguesa, mas para construção de uma Pedagogia da Terra concreta que, por meio de uma práxis libertadora, modifique o mundo. $\mathrm{O}$ discurso de Kolling ${ }^{2}$ explicita muito bem essa questão quando reforça que;

\footnotetext{
O propósito é conceber uma educação básica do campo, voltada aos interesses e ao desenvolvimento sócio-cultural e econômico dos povos que habitam e trabalham no campo, atendendo às suas diferenças históricas e culturais para que vivam com dignidade e para que, organizados, resistam contra a expulsão e a expropriação. Não basta ter escolas do campo, são necessários escolas com um projeto políticopedagógico vinculado às causas, aos desafios, aos sonhos, à história e à cultura do povo trabalhador do campo. (KOLLING, 1999, p. 29).
}

É um dos organizadores do relatório da Conferência Nacional Por uma Educação Básica do Campo, que resultou na proposta de Educação básica do campo. 
Sim, a Educação do Campo tem vinculação com uma classe social: dos trabalhadores, com a classe dos sem (dos Sem-Terra, sem moradia, sem acesso à educação, sem acesso a saúde) e por ter nascido em meio às contradições históricas é um enfrentamento diante da imposição do capital que quer cada vez mais transformar a educação e os espaços educacionais em extensão da indústria.

Ou seja, formam-se pessoas não para tornarem-se sujeitos capazes de produzir sua própria história, mas sim, transformam as pessoas uma extensão da máquina e sendo assim reproduz os valores capitalistas. É o que afirma o filósofo Istiván Mészáros:

\begin{abstract}
A educação institucionalizada, especialmente nos últimos 150 anos, Serviu - no seu todo - ao propósito de não só fornecer os conhecimentos e o pessoal necessário à máquina produtiva em expansão do sistema do capital, como também gerar e transmitir um quadro de valores que legitima os interesses dominantes, como se não pudesse haver nenhuma alternativa à gestão da sociedade, seja na forma "internalizada" (isto é, pelos indivíduos devidamente "educados" e aceitos) ou através e uma dominação estrutural e uma subordinação hierárquica e implacavelmente impostas (MÉSZÁROS, 2008, p. 35).
\end{abstract}

Percebemos que, com base no pensamento do autor, desde o surgimento do capitalismo, a educação está atrelada à forma de exploração capitalista. Portanto, ao se pensar em um novo modo de educação humana, deve-se levar em conta que essa mudança deve estar vinculada à mudança do modo de produção. E o movimento em torno da Educação do Campo, como pontuou Capitani,

\footnotetext{
Nasce entre as contradições históricas da luta de classes na atualidade, especificamente a luta que se dá no Campo brasileiro entre os camponeses e o agronegócio (expressão maior do capitalismo mundial da atualidade), na luta por direitos sociais como a terra, a saúde e a educação. (CAPITANI, 2014, p.15).
}

Isso quer dizer que, em última análise, a Educação do Campo explicita as contradições que existem no interior do sistema capitalista. Ela nasce não somente no sentido de pensar uma educação restrita ao campo, mas também no sentido de se vincular com a transformação social. Tanto é assim que a educação que está sendo forjada pelos movimentos sociais do campo tem uma profunda ligação com a luta pela democratização da terra e com a justa distribuição da riqueza produzida pelos trabalhadores de uma forma geral.

Mas porque os movimentos sociais do campo - especialmente o Movimento dos Trabalhadores Rurais Sem Terra (MST) - lutam pela educação? Assim como a terra, a 
educação também está em disputa por dois projetos de classes sociais: o projeto da classe capitalista, que é hegemônico, e o projeto da classe trabalhadora, que ainda não se tornou real, mas está sendo construído no embate da luta de classes

Mas quando é que nasce a proposta de uma nova educação denominada Educação do Campo? Juntamente com a luta pela nova Constituição, seguiu-se uma ampla articulação dos povos do campo por direitos, por exemplo, a conquista da terra, a democratização da educação. E se tratando especificamente da educação, os povos do campo se propuseram não apenas a discutir em ter escolas no campo, mas em construir um novo conceito de educação para o campo.

Figura 2: Jovens do Campo em Manifestações

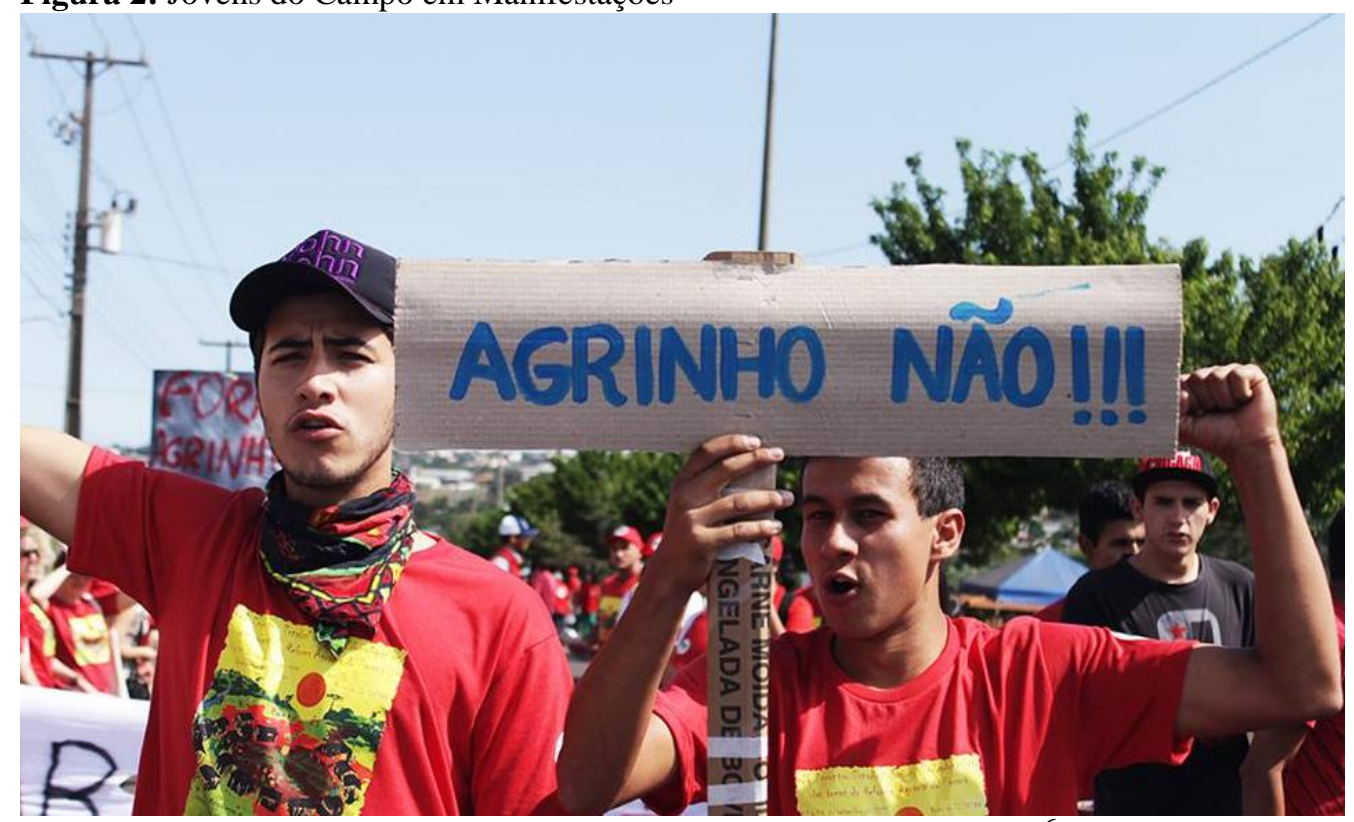

Fonte: Articulação Paranaense por uma Educação do Campo ${ }^{6}$.

Somente a partir da Constituição de 1988 é que a educação é promulgada como direito de todos. Isso se torna fundamental para que se discuta cada vez mais acesso ao direito à educação que historicamente foi negado para os trabalhadores e em maior grau aos trabalhadores do campo. E assim, por meio de mobilizações, muitas lutas, não somente pelo MST, mas por muitos outros movimentos do campo, professores, intelectuais, com a nova Lei de Diretrizes e Bases da Educação Nacional (n9394/96), se reconhece que os povos que

\footnotetext{
${ }^{6}$ https://www.facebook.com/articulacaopr/photos/a.406271369394549.90104.371946329493720/994060753948 938/?type=3\&theater. Acessado em 05/06/2016.
} 
vivem no campo têm seu jeito próprio de aprendizagem, que existem diversidades sociais e culturais.

Em 1998, foi articulada a Conferência Nacional por uma Educação Básica do Campo (Por Uma Educação do Campo: Declaração 2002, p. 15). Essa conferência teve a importância de trazer em seu bojo a formalidade do nascimento do Movimento Por Uma Educação do Campo e teve a participação de vários seguimentos nacionais: Movimento dos Trabalhadores Rurais Sem Terra (MST), pela Conferência Nacional dos Bispos do Brasil (CNBB), Organização das Nações Unidas (UNESCO), Universidade de Brasília (UnB), e Fundo das Nações Unidas para a Infância (UNICEF).

O termo "por uma educação básica do campo" trouxe a realidade alarmante em que vivemos, pois naquela época - anos 1990 -, e atualmente, o direito dos camponeses em ter um espaço educacional no meio onde vivem (o campo) ainda não lhes foi assegurado.

Não obstante, no ano de 2002, outro passo importante foi dado. Nesse ano, instituíram-se as Diretrizes Operacionais para a Educação Básica nas Escolas do Campo, legitimando as escolas do campo articuladas às questões inerentes a realidade, dando importância aos saberes dos estudantes adquiridos ao longo de suas vidas, assim como, a valorização da memória coletiva, estudos direcionado para o mundo do trabalho (Resolução CNE/CEB 1, de Abril de 2002, p. 81).

Os movimentos sociais do campo, por sua vez, realizaram a segunda Conferência Nacional Por uma Educação do Campo (Por Uma Educação do Campo, 2002, p.19). O termo "por uma educação do campo" traz em si a combinação de duas lutas: garantir de forma incondicional à educação e à escolarização no campo e por uma escola que seja no e do campo, ou seja, que esteja no espaço onde os povos do campo vivem e que também esteja vinculada à história, à cultura e à expressão de vida desses povos. Com relação ao conceito da Educação do Campo, Caldart ressalta:

O conceito de Educação do Campo é novo, mas já está em disputa, exatamente porque o movimento da realidade que ele busca expressar é marcado por contradições mais fortes. Para nós o debate conceitual é importante à medida que nos ajuda a ter mais claro quais são os embates e quais os desafios práticos que temos pela frente. No debate teórico, o momento atual não nos parece ser o de buscar "fixar" um conceito, fechá-lo em um conjunto de palavras: porque isso poderia matar a ideia de movimento da realidade que ele quer apreende, abstrair, e que nós precisamos compreender com mais rigor justamente para poder influir ou intervir no seu curso (CALDART, 2010, p. 69). 
Percebemos, então, que a Educação do Campo nasce com a perspectiva da transformação do velho para o do devir do novo, como crítica da realidade trazendo à tona os problemas que existem no sistema educacional brasileiro, sobretudo aquele que existe no campo brasileiro. E, segundo Caldart, "o conceito de Educação do Campo tem raiz na sua materialidade de origem e no movimento histórico da realidade a que se refere" (CALDART, 2010, p. 69). A autora explicita essa realidade:

1. O campo no Brasil está em movimento. Há tensões, lutas sociais, organizações e movimentos de trabalhadores e trabalhadoras da terra que estão mudando o jeito da sociedade olhar para o campo e seus sujeitos.

2. A educação Básica do Campo está sendo produzida neste movimento, nesta dinâmica social, que é também um movimento sociocultural de humanização das pessoas que dele participam.

3. Existe uma nova prática de Escola que está sendo gestada neste movimento. Nossa sensibilidade de educadores já nos permitiu perceber que existe algo diferente e que pode ser uma alternativa em nosso horizonte de trabalhador, de ser humano. Precisamos aprender a potencializar os elementos presentes nas diversas experiências, e de transformá-los em um movimento consciente de construção das escolas do campo como escolas que ajudem neste processo mais amplo de humanização, e de reafirmação dos povos do campo como sujeitos de seu próprio destino, de sua própria história (CALDART, 2010, p. 89-90).

Verificamos, como base na citação em destaque, a realidade na qual se coloca a Educação do Campo: na luta social dos trabalhadores do campo em conflito com uma realidade que os coloca à margem da sociedade na medida em que nega direitos como, por exemplo, o acesso à terra e à educação (CAPITANI, 2010). Luta-se, assim, por uma educação que ocorra no lugar onde as pessoas produzem sua própria existência (CALDART, 2010), que seja no e do campo: "No: o povo tem o direito a ser educado no lugar onde vive; Do: o povo tem direito a uma educação pensada desde o seu lugar e com a sua participação, vinculada a sua cultura e às suas necessidades humanas e sociais" (CALDART, 2010, p. 26).

Então, vinculada a essa realidade, a esse movimento dialético, a Educação do Campo coloca-se na discussão e na construção de uma nova escola. Uma escola que esteja vinculada com a formação humana e não apenas com instrumentalização, de trabalhar de forma planejada as diferentes dimensões do desenvolvimento humano integral (CALDART 2010), sempre tendo em vista que esse processo não se faz de forma individualizada, mas sim com ampla participação das pessoas que se envolvem com o processo educativo (professores, alunos, pais e comunidade) discutido formas educativas que contrapõe a lógica atual de educação que existe na sociedade atual que está fundamentada no individualismo, no egoísmo, na concorrência e no consumismo. 
O espaço escolar definitivamente tem o papel contribuir na formação de seres humanos capazes de transformar o meio no qual estão inseridos e não apenas serem sujeitos inseridos e acomodados com o atual estado de coisas. É também o que nosso mestre da Educação Popular, Paulo Freire (2006), nos disse em suas reflexões sobre a pedagogia do oprimido: a escola não transforma a realidade, mas pode ajudar a formar os sujeitos capazes de fazer a transformação, da sociedade, do mundo, de si mesmo. (FREIRE, 2006).

Esse é o projeto dos movimentos sociais do campo, especialmente o MST, que apesar de ser tachado como grupo de "baderneiros", de "terroristas", vem construindo um amplo debate sobre a transformação social nos espaços dos assentamentos, acampamentos e lugares de formação, como escolas e universidades.

\section{CONSIDERAÇÕES FINAIS}

O marxismo tem trazido para a classe trabalhadora muitos ensinamentos, mostrando que a história da humanidade é a história da luta de classes, e que, para romper com a hegemonia do capitalismo, é necessário que a classe trabalhadora tenha um projeto paralelo, rompendo definitivamente com o modo de produção atual. O materialismo histórico dialético é um método de análise que possibilita aos trabalhadores em geral a perceber o mundo, e acima de tudo a transforma-lo. A Educação do Campo ultrapassa os limites das escolas, constitui-se uma ferramenta que impulsiona os sujeitos do campo a lutarem por espaços muitas vezes reprimidos pelo sistema agrário brasileiro. Nesse sentido, que os movimentos sociais do campo, representa elemento chave para elencar este novo horizonte de lutas e embates políticos em torno do conceito de Educação do Campo.

Trabalhar um conceito de educação além do que já está exposto pelo Estado prescreve um novo paradigma de educação, que garantirá a sobrevivência dos povos do campo. A Educação do Campo garante resgaste dos valores humanos, a solidariedade de suas representações culturais. É nesse sentido que a Educação do Campo rompe com o modelo atual de educação, dando-lhes possiblidade de pensar o seu próprio meio de existência através de sua realidade. O Espaço rural representará não apenas um lugar de produção de alimentos para os centros urbanos, mas reestruturará a possiblidade e os modos de vidas, muitas vezes abandonados e desestruturados pelo modo de produção capitalista.

Concluímos, então, que, para que a educação seja de fato transformada, é necessário que ela esteja ligada a um projeto mais amplo de transformação social. É imprescindível que 
ela venha ao encontro do projeto da classe trabalhadora, que ela seja gestada para a libertação humana.

Faz-se necessário, também, que a escola seja mais que escola, a universidade precisa ser mais que a universidade. Precisa ser parte de uma totalidade formadora mais ampla, porque as lutas pedagógicas não substituem as lutas sociais e políticas mais amplas.

\section{REFERÊNCIAS}

CALDART; Roseli Salete (Org.). Caminhos para a transformação da Escola: reflexões desde práticas da licenciatura em Educação do Campo. São Paulo: Expressão Popular $1^{\circ}$ Ed., 2010.

CAPITANI, Nelson. Transformação da realidade da organização escolar: contradição social e possibilidade de mudança. Cascavel, 2014. 46 p. TCC (Licenciatura em Educação do Campo) - Universidade Estadual do Oeste do Paraná, Cascavel, 2014.

CONFERÊNCIA NACIONAL POR UMA EDUCAÇÃO DO CAMPO. Por uma Educação do Campo: declaração 2002. In: COLLING; Edgar Jorge, CERIOLI; Paulo Ricardo, CALDART; Roseli Salete (Orgs). Educação do Campo: identidade e políticas públicas. Brasília, DF: articulação nacional por uma educação do campo, 2002. Coleção Por Uma Educação do Campo, $\mathrm{n}^{\circ} 4$.

FREIRE, Paulo. Pedagogia do oprimido. 44. ed. Rio de Janeiro: Paz e Terra, 2006.

KOLLING, Edgar Jorge. Por uma Educação básica do campo. Fundação Universidade de Brasília, 1999.

MARX, Karl. Contribuição para a crítica da economia política. 3. ed. Lisboa: Estampa, 1973.

O 18 Brumário e carta a Kugelmann. 6. ed. Rio de Janeiro: Paz e Terra, 1997.

; ENGELS, Friedrich. Crítica da educação e do ensino. Lisboa: Moraes, 1978.

; __ A ideologia alemã: (I-Zeuerbach). 9. ed. São Paulo: HUCITEC, 1993.

; _ A sagrada família, ou, A crítica da Crítica crítica contra Bruno Bauer e consortes. São Paulo: Boitempo, 2003.

MÉZÁROS, István. A Educação Para Além do Capital. São Paulo - Boitempo - $2^{\mathrm{a}}$ Ed. 2008. 